\title{
Role of lymphatic invasion in the prognosis of patients with clinical node-negative and pathologic node-positive lung adenocarcinoma
}

\author{
Takahiro Mimae, MD, PhD, ${ }^{\mathrm{a}}$ Yasuhiro Tsutani, $\mathrm{MD}, \mathrm{PhD},{ }^{\mathrm{a}}$ Yoshihiro Miyata, $\mathrm{MD}, \mathrm{PhD},{ }^{\mathrm{a}}$ \\ Tomoharu Yoshiya, MD, ${ }^{\mathrm{a}}$ Yuta Ibuki, MD, ${ }^{\mathrm{a}}$ Kei Kushitani, MD, PhD, ${ }^{\mathrm{b}}$ Yukio Takeshima, MD, PhD, \\ Haruhiko Nakayama, MD, PhD, ${ }^{\mathrm{c}}$ Sakae Okumura, MD, PhD, ${ }^{\mathrm{d}}$ Masahiro Yoshimura, MD, PhD, ${ }^{\mathrm{e}}$ and \\ Morihito Okada, MD, $\mathrm{PhD}^{\mathrm{a}}$
}

Objective: Some patients with clinical T1 N0 M0 lung adenocarcinoma have pathologic lymph node metastasis. However, neither the precise prognosis nor the factors predictive of the prognosis of such patients have yet been identified.

\begin{abstract}
Methods: Our study included 609 patients with clinical T1 N0 M0 lung adenocarcinoma; 568 (93.3\%) pathologic node negative [pN(-)] and $41(6.7 \%)$ pathologic node positive $[\mathrm{pN}(+)]$ patients, diagnosed after complete surgical resection. The association between prognosis and pathologic findings was analyzed retrospectively.

Results: $\mathrm{pN}(+)$ patients had a significantly lower lepidic growth component ratio (10\% vs $50 \%$ ), a higher lymphatic invasion (LI) rate (68\% vs $11 \%)$, vessel invasion rate (59\% vs $14 \%)$, and visceral pleural invasion rate $(29 \%$ vs $9 \%$ ), compared with $\mathrm{pN}(-)$ patients (all $P \mathrm{~s}<.001)$. Surprisingly, 13 of $41(32 \%) \mathrm{pN}(+)$ patients showed no LI. In $\mathrm{pN}(-)$ patients, a multivariate analysis of recurrence-free survival revealed that lower lepidic growth component ratio, and lymphatic, vessel, and pleural invasion were significantly correlated with a poor prognosis $(P=.008, .045, .031$, and .024). However, in $\mathrm{pN}(+)$ patients, the multivariate analysis of recurrence-free survival showed that only LI was a significant independent prognostic factor $(P=.037)$. The 5-year recurrence-free survival rates were as follows: $91.2 \%$ for $\mathrm{pN}(-) / \mathrm{LI}(-)$ patients, $68.2 \%$ for $\mathrm{pN}(-) /$ $\mathrm{LI}(+)$ patients, $63.5 \%$ for $\mathrm{pN}(+) / \mathrm{LI}(-)$ patients, and $41.9 \%$ for $\mathrm{pN}(+) / \mathrm{LI}(+)$ patients. LI status stratified the prognosis not only in patients with no nodal metastasis but also in those with metastasis.
\end{abstract}

Conclusions: LI, which is not always present in node-positive adenocarcinoma, is an important prognostic variable in patients with node involvement. (J Thorac Cardiovasc Surg 2014;147:1820-6)

\section{Earn CME credits at}

http://jtcvs.com/cme/home

Fluorescence deoxyglucose (FDG) positron emission tomography (PET) is commonly used for preoperative assessment of primary tumors, lymph nodes, and distant metastasis to determine staging and treatment strategy, ${ }^{1-3}$ thereby improving the accuracy of the definition of clinical stage IA compared with only computed tomography assessment. ${ }^{1}$ This has changed the population of patients with clinical stage IA lung adenocarcinoma. ${ }^{1,4-7}$ However, some clinical lymph node-negative $[\mathrm{cN}(-)]$

\footnotetext{
From the Departments of Surgical Oncology a and Pathology, ${ }^{\mathrm{b}}$ Hiroshima University, Hiroshima, Japan; Department of Thoracic Surgery, ${ }^{\mathrm{c}}$ Kanagawa Cancer Center, Yokohama, Japan; Department of Thoracic Surgery, ${ }^{\mathrm{d}}$ Cancer Institute Hospital, Tokyo, Japan; and Department of Thoracic Surgery, ${ }^{\mathrm{e}}$ Hyogo Cancer Center, Akashi, Japan.

Disclosures: Authors have nothing to disclose with regard to commercial support. Received for publication Aug 5, 2013; revisions received Oct 22, 2013; accepted for publication Nov 22, 2013; available ahead of print Feb 7, 2014.

Address for reprints: Morihito Okada, MD, PhD, Department of Surgical Oncology, Hiroshima University, Hiroshima, Japan, 1-2-3 Kasumi, Minami-ku, Hiroshima, 734-8551, Japan (E-mail: morihito1217@hiroshima-u.ac.jp).

$0022-5223 / \$ 36.00$

Copyright (c) 2014 by The American Association for Thoracic Surgery

http://dx.doi.org/10.1016/j.jtcvs.2013.11.050
}

patients show positive pathologic lymph node $[\mathrm{pN}(+)]$ metastasis. It is speculated that a $\mathrm{cN}(-)$ but $\mathrm{pN}(+)$ status indicates an initial lymph node metastatic condition, because the accumulation of FDG in the lymph node could be significantly higher in patients with massive lymph node metastasis. Therefore, $\mathrm{cN}(-) / \mathrm{pN}(+)$ patients may have a better prognosis than $\mathrm{cN}(+) / \mathrm{pN}(+)$ patients, or a similar prognosis to $\mathrm{cN}(-) / \mathrm{pN}(-)$ patients. In addition, no studies have identified the prognostic factors in $\mathrm{cN}(-) / \mathrm{pN}(+)$ patients.

In our study, we evaluated the clinicopathologic findings and prognosis of patients with clinical T1 N0 M0 lung adenocarcinoma according to lymph node status, or other pathologic status. First, we examined the pathologic findings to identify predictive factors for recurrence-free survival (RFS) among patients with clinical stage IA lung adenocarcinoma. Multivariate analysis revealed that lymphatic invasion (LI) status was a predictive factor, both in patients with and without node involvement. Next, we assessed the prognosis of patients with and without lymph node involvement according to LI status. The results highlight the importance of the LI status in patients with clinical T1 N0 M0 lung adenocarcinoma.

\section{MATERIALS AND METHODS Patient Population}

Our study included 611 patients who underwent complete surgical resection of clinical stage IA lung adenocarcinoma at the Hiroshima University 


\author{
Abbreviations and Acronyms \\ $\mathrm{CT}=$ computed tomography \\ $\mathrm{FDG}=$ fluorescence deoxyglucose \\ $\mathrm{GGO}=$ ground glass opacity \\ $\mathrm{HU}=$ Haunsfield unit \\ LC = lepidic component \\ LI = lymphatic invasion \\ OS $=$ overall survival \\ PET $=$ positron emission tomography \\ RFS = recurrence-free survival \\ SUV $=$ standardized uptake value
}

Hospital (Hiroshima, Japan), the Kanagawa Cancer Centre (Yokohama, Japan), the Cancer Institute Hospital (Tokyo, Japan), and the Hyogo Cancer Centre (Akashi, Japan) between April 2007 and December 2010. Approval was given by the institutional review boards of the participating institutions, all of which waived the requirement for informed consent from individual patients for this retrospective review of the prospective database. Two patients were excluded because they lacked a lepidic component (LC) ratio. The data from the remaining 609 patients were analyzed retrospectively. High-resolution computed tomography (CT) and FDG-PET/CT, followed by a curative $\mathrm{R} 0$ resection were performed for all patients staged according to the TNM Classification of Malignant Tumours. ${ }^{8}$ Endobronchial ultrasonography or mediastinoscopy was not performed routinely because all patients underwent preoperative high-resolution CT and FDG-PET/CT; the high-resolution CT results showed no swelling of mediastinal or hilar lymph nodes and FDG-PET revealed no accumulation of FDG in those lymph nodes. Lymph node swelling was defined when the diameter of a minor axis is larger than $10 \mathrm{~mm}$. Sublobar resection was performed in cases of complete removal of the disease with appropriate surgical margins for a peripheral T1a N0 M0 tumor. Wedge resection without lymph node assessment was performed for ground glass opacity (GGO) tumors on highresolution $\mathrm{CT}$, which was regarded as a node-negative and noninvasive tumor in a prospective study. ${ }^{9}$ Segmentectomy with hilar and mediastinal lymph node dissection were performed for a GGO-mixed tumor. If lymph node involvement was detected on an intraoperative frozen section of any lymph node, the procedure was converted to a standard lobectomy. All other patients underwent a standard lobectomy. The inclusion criteria included preoperative staging determined by high-resolution CT and FDG-PET/ CT, curative surgery without any induction therapy, and a definitive histopathologic diagnosis of lung adenocarcinoma. Patients with incompletely resected tumors (R1 or R2), and those with multiple tumors or previous lung surgery, were excluded from the data set.

\section{Pathology Studies}

Sections were fixed with $10 \%$ formalin and embedded in paraffin. Consecutive $4-\mu \mathrm{m}$ sections were cut and 1 slice per $5 \mathrm{~mm}$ was examined under a microscope for the pathologic assessment. Histologic diagnosis and staging was based on the latest edition of the World Health Organization classification scheme. ${ }^{10}$ The histologic type of adenocarcinoma and the presence of lymphatic involvement were determined using hematoxylin-eosin stained tissue. If the findings could not be determined by hematoxylin-eosin staining alone, immunohistochemical staining was carried out as necessary. An LC ratio was defined as the proportion of LC area relative to the entire tumor. LI and blood vessel invasion were assessed by immunohistochemistry for D2-40, which stains lymphatic ducts, and Van Gieson staining of the elastic fiber of the vessels. LI and blood vessel invasion were determined when spreading through or penetration was detected as an extension of a malignant neoplasm. To evaluate pleural invasion, elastic tissue fibers were subjected to Van Gieson staining. Pleural invasion was determined if cancer cells had invaded beyond the elastic layer, including invasion into the visceral pleural surface, or neighboring organs. Histologic examinations were determined by pathologists from each institution for the purposes of this study.

\section{HRCT}

A 16-row multidetector CT was used to obtain chest images. For highresolution images of the tumors, the following parameters were used: 120 $\mathrm{kVp}, 200 \mathrm{~mA}, 1$ to $2 \mathrm{~mm}$ section thickness, $512 \times 512$ pixel resolution, 0.5 to 1.0 second scanning time, a high spatial reconstruction algorithm with a $20 \mathrm{~cm}$ field of view, and mediastinal (level, 40 Haunsfield unit [HU]; width, $400 \mathrm{HU}$ ) and lung (level, $-600 \mathrm{HU}$; width, $1600 \mathrm{HU}$ ) window settings. GGO was defined as a misty increase in lung attenuation that did not obscure underlying vascular markings. CT scans were reviewed and tumor sizes determined by radiologists from each institution.

\section{FDG-PET/CT}

Patients were instructed to fast for at least 4 hours before intravenous injection of 74 to $370 \mathrm{MBq}$ FDG and then to relax for at least 1 hour before the FDG-PET/CT scan. For imaging, Biograph Sensation 16 (Siemens Healthcare, Erlangen, Germany), Aquiduo (Toshiba Medical Systems Corporation, Tochigi, Japan), or Discovery ST (GE Healthcare, Little Chalfont, United Kingdom) integrated 3-dimensional PET/CT scanners were used. Low-dose nonenhanced CT images of 2 to $4 \mathrm{~mm}$ section thickness were taken from the head to the pelvis of each patient. An anthropomorphic body phantom (NEMA NU2-2001; Data Spectrum Corp, Hillsborough, $\mathrm{NC)}$ was used to minimize variations in standardized uptake values (SUVs) among the institutions. ${ }^{11,12}$ The original SUV $_{\max }$ values were determined by radiologists from each institution for the purposes of this study. On FDG-PET/CT images, all lymph nodes in the thorax with FDG uptake no greater than the normal background activity of the mediastinal blood pool-the $\mathrm{SUV}_{\max }$ of which was $<1.5$, regardless of size-were considered cN0. A lymph node where the $\mathrm{SUV}_{\max }$ was $\geq 1.5$ or more was considered "suspicious for malignancy." However, even lymph nodes with high FDG uptake, when they showed higher attenuation than mediastinal structures (great vessels) or benign calcification (central, nodular, diffuse, or popcorn-like), were also considered benign. ${ }^{13}$

\section{Follow-up Evaluation}

All patients who underwent lung resections were followed-up from the day after surgery. Postoperative follow-up procedures, including a physical examination and chest radiograph every 3 months and chest and abdominal CT examinations every 6 months, were performed for the first 2 years. Thereafter, a physical examination and chest radiograph were performed every 6 months, and a chest CT examination was performed annually.

\section{Statistical Analyses}

Patients with clinical stage IA lung adenocarcinoma were included in the analysis. A Mann-Whitney $U$ test was used to compare continuous variables and the $\chi^{2}$ test or Fisher exact test was used for categorical variables. RFS was defined as the length of time after primary surgical treatment for a cancer ends that the patient survived without any sign or symptom of the cancer. Recurrence was defined as patients having symptoms caused by recurring cancer and suspicious lesions that were diagnosed as recurrent tumors by biopsies. If suspicious lesions were not diagnosed as recurrence, by biopsy, the "recurrence" was comprehensively and clinically defined by radiographic findings, including CT and FDG-PET/CT. RFS and overall survival (OS) curves were calculated using the Kaplan-Meier method. Univariate survival analysis was performed using the log-rank test for comparisons of curves. A Cox regression model was used to calculate $P$ values and hazard ratios in the univariate and multivariate analyses. The prognostic analysis was performed during August 2012. All statistical analyses were 
performed using EZR (Saitama Medical Centre, Jichi Medical University, Saitama, Japan), ${ }^{14}$ which is a graphical user interface for R (The R Foundation for Statistical Computing, version 2.13.0, Vienna, Austria). More precisely, it is a modified version of R Commander (version 1.6-3), which includes statistical functions frequently used in biostatistics.

\section{RESULTS}

\section{Clinical Outcomes in Patients With Lung Adenocarcinoma}

The median follow-up time was 41.6 months. Lobectomy, segmentectomy, and wedge resection were performed in 375,97 , and 137 patients, respectively. The 30-day mortality rate was $0 \%$. As shown in Table 1,41 patients $(6.7 \%)$ had lymph node metastasis in the clinical stage IA lung adenocarcinoma cohort. No significant difference between $\mathrm{pN}(-)$ and $\mathrm{pN}(+)$ patients was detected in terms of age, sex, and carcinoembryonic antigen value, whereas a marginal difference was seen for tumor size on preoperative high-resolution CT. Regarding the clinical variables, lower GGO ratios and higher $\mathrm{SUV}_{\max }$ were observed in the $\mathrm{N}+$ group compared with the $\mathrm{N}$ - group. In terms of pathologic variables, a lower LC ratio and higher positive rate of LI, blood vessel invasion, and pleural invasion were detected in $\mathrm{pN}(+)$ patients. Thirteen of $41 \mathrm{pN}(+)$ patients showed no LI. As shown in Figure 1, $A$, clinical stage IA lung adenocarcinoma patients with lymph node metastasis had a lower RFS rate than those without lymph node metastasis $(P<.001)$.

\section{Univariate and Multivariate Analyses of Prognosis According to Pathologic Variables, by Lymph Node Status}

Univariate and multivariate analyses of the clinical and pathologic variables were performed to ascertain the most important predictive factor. Univariate analyses were performed on RFS and OS, whereas further analyses, including multivariate analyses, were performed on RFS because OS was more immature than RFS. The pathologic variables included LC ratio, LI status, blood vessel invasion status, pleural invasion status, and lymph node status. For the LC ratio, $30 \%$ was used as a threshold because this is the borderline for cT1 N0 M0 lung adenocarcinoma classified as a high- or low-grade malignancy. ${ }^{2}$ Univariate analysis revealed that $\mathrm{pN}(+)$ patients with $\mathrm{LI}$ positive status $[\mathrm{LI}(+)]$ had a marginally poorer prognosis $(P=.059)$, whereas a lower $\mathrm{LC}$ ratio and $\mathrm{LI}+$ status, blood vessel invasion, pleural invasion, or lymph node metastasis was significantly correlated with a poor prognosis in both all patients in this cohort, and in $\mathrm{pN}(-)$ patients (Table 2). Additionally, multivariate analysis showed that only LI positive status was a prognostic factor in $\mathrm{pN}(+)$ patients $(P=.037)$, whereas a lower LC ratio and positive LI status, blood vessel invasion, pleural invasion, or lymph node metastasis were prognostic factors in both all patients and $\mathrm{pN}(-)$ patients (Table 3 ).
TABLE 1. Clinicopathologic findings in patients with clinical stage IA lung adenocarcinoma with or without lymph node metastasis

\begin{tabular}{|c|c|c|c|}
\hline Finding & $\begin{array}{l}\text { Node negative } \\
\quad(\mathrm{n}=\mathbf{5 6 8})\end{array}$ & $\begin{array}{c}\text { Node positive } \\
\quad(\mathrm{n}=41)\end{array}$ & $P$ value \\
\hline \multicolumn{4}{|l|}{ Age } \\
\hline Median & 66 & 65 & .33 \\
\hline Interquartile range & $60.75-73$ & $56-73$ & \\
\hline \multicolumn{4}{|l|}{ Sex } \\
\hline Female & $322(57 \%)$ & $22(54 \%)$ & .19 \\
\hline Male & $246(43 \%)$ & $19(46 \%)$ & \\
\hline \multicolumn{4}{|l|}{ CEA } \\
\hline Median & 2.5 & 3.6 & .25 \\
\hline Interquartile range & $1.5-3.6$ & $1.1-113.8$ & \\
\hline \multicolumn{4}{|l|}{ Size* } \\
\hline Median & 2.0 & 2.2 & .060 \\
\hline Interquartile range & $1.5-2.4$ & $2.55-4.2$ & \\
\hline \multicolumn{4}{|l|}{$\mathrm{GGO} \uparrow$ ratio } \\
\hline Median & 40 & 0 & $<.001$ \\
\hline Interquartile range & $10-80$ & $0-10$ & \\
\hline \multicolumn{4}{|l|}{ SUV max } \\
\hline Median & 1.5 & 3.6 & $<.001$ \\
\hline Interquartile range & $0.9-2.6$ & 2.3-4.9 & \\
\hline \multicolumn{4}{|l|}{ LC ratio } \\
\hline Median & 50 & 10 & $<.001$ \\
\hline Interquartile range & $10-90$ & $0-20$ & \\
\hline \multicolumn{4}{|l|}{ Lymphatic invasion } \\
\hline Negative & $507(89 \%)$ & $13(32 \%)$ & $<.001$ \\
\hline Positive & $61(11 \%)$ & $28(68 \%)$ & \\
\hline \multicolumn{4}{|l|}{ Blood vessel invasion } \\
\hline Negative & $488(86 \%)$ & $17(41 \%)$ & $<.001$ \\
\hline Positive & $80(14 \%)$ & $24(59 \%)$ & \\
\hline \multicolumn{4}{|l|}{ Pleural invasion } \\
\hline Negative & $515(91 \%)$ & $29(71 \%)$ & $<.001$ \\
\hline Positive & $53(9 \%)$ & $12(29 \%)$ & \\
\hline
\end{tabular}

$C E A$, Carcinoembryonic antigen; $G G O$, ground-glass opacity; $S U V$, standardized uptake value; $L C$, lepidic component. *Tumor size on the high-resolution computed tomography scan. $\nmid \mathrm{GGO}$ ratio on the high-resolution computed tomography scan.

Next, we assessed the RFS of $\mathrm{pN}(-)$ and $\mathrm{pN}(+)$ patients according to their LI status. In both $\mathrm{pN}(-)$ and $\mathrm{pN}(+)$ patients, RFS rates were lower in $\mathrm{LI}(+)$ status compared with $\mathrm{LI}$ negative status $[\mathrm{LI}(-)](P<.001$ and $P=.059)$ (Figure 1 , $B$ and $C$ ). The 3 -year RFS and OS rates for each group was as follows: $\mathrm{pN}(-) / \mathrm{LI}(-) 93.4 \%$ and $96.7 \%, \mathrm{pN}(-) /$ $\mathrm{LI}(+) \quad 70.8 \%$ and $85.1 \%, \mathrm{pN}(+) / \mathrm{LI}(-) \quad 84.6 \%$ and $92.3 \%$, and $\mathrm{pN}(+) / \mathrm{LI}(+) 47.9 \%$ and $75.0 \%$, respectively (Table 2 and Figure $1, B-F$ ). No significant difference was detected between the $\mathrm{pN}(+) / \mathrm{LI}(-)$ and $\mathrm{pN}(-) / \mathrm{LI}(+)$ patients for RFS $(P=.62$; Figure $1, D)$, whereas $\mathrm{pN}(+) /$ $\mathrm{LI}(-)$ and $\mathrm{pN}(-) / \mathrm{LI}(-)$ patients, $\mathrm{pN}(+) / \mathrm{LI}(+)$ and $\mathrm{pN}(-) /$ $\mathrm{LI}(-)$ patients, and $\mathrm{pN}(+) / \mathrm{LI}(+)$ and $\mathrm{pN}(-) / \mathrm{LI}(+)$ patients exhibited significantly different RFS values $(P=.022$, $<.001$, and .011, respectively).

\section{Clinicopathologic Findings in $\mathbf{N}+$ Patients}

In $\mathrm{N}+$ patients, there were no significant differences between the $\mathrm{LI}(-)$ and $\mathrm{LI}(+)$ groups in terms of age, sex, 

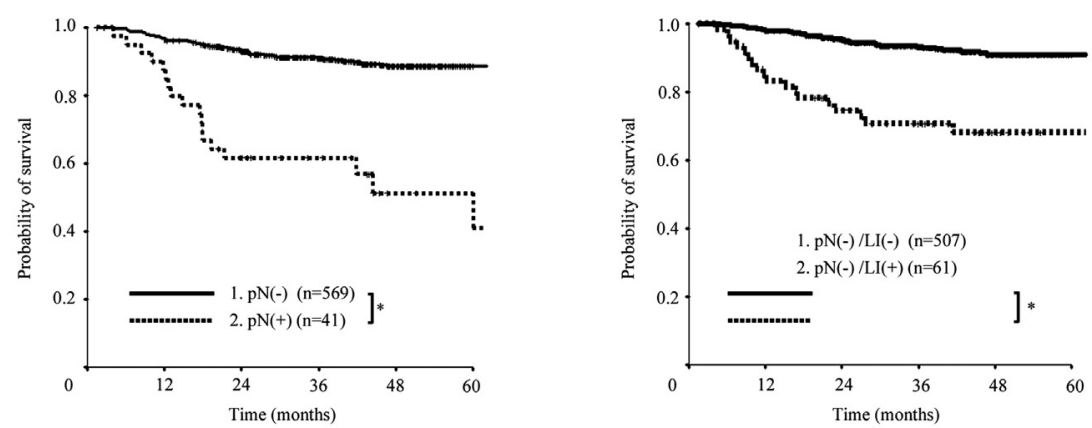

Patients at risk

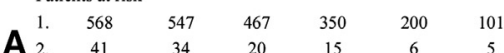
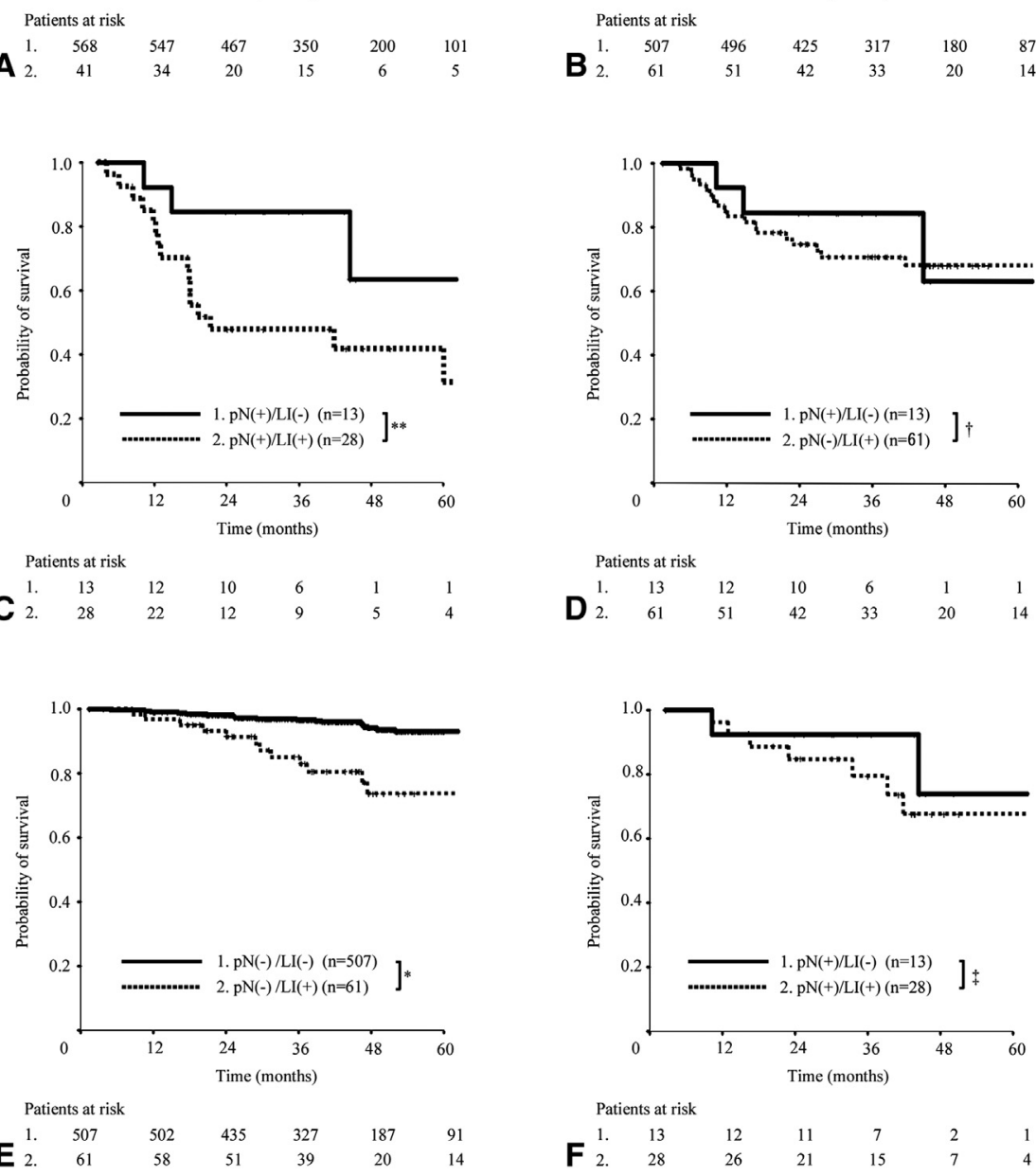

FIGURE 1. Kaplan-Meier recurrence-free survival (A-D) and overall survival (E and F) curves in patients with clinical stage IA lung adenocarcinoma according to pathologic lymph node status and lymph node metastasis and lymphatic invasion $(L I)$ status. A, Patients are classified into pathologic lymph node metastasis negative $(\mathrm{pN}[-])$ and positive $(\mathrm{pN}[+])$ groups. B, The $\mathrm{pN}(-)$ patients are classified into a lymphatic permeation negative (pN[-]/LI[-]) group and a lymphatic permeation positive $(\mathrm{pN}[-] \mathrm{LI}[+])$ group. $\mathrm{C}$, The $\mathrm{pN}(+)$ patients are classified into a lymphatic permeation negative $(\mathrm{N}[+] \mathrm{LI}[-])$ group and a lymphatic permeation positive $(\mathrm{N}[+] \mathrm{LI}[+])$ group. $\mathrm{D}$, Recurrence-free survival curves of $\mathrm{pN}(+) \mathrm{LI}(-)$ and $\mathrm{pN}(-) \mathrm{LI}(+)$ patients are shown. $\mathrm{E}$, The $\mathrm{pN}(-)$ patients are classified into a $\mathrm{pN}(-) / \mathrm{LI}(-)$ group and a $\mathrm{pN}(-) \mathrm{LI}(+)$ group. $\mathrm{F}$, The $\mathrm{pN}(+)$ patients are classified into an $\mathrm{N}(+) \mathrm{LI}(-)$ group and an $\mathrm{N}(+) \mathrm{LI}(+)$ group. $* P<.001 ; * * P=.059 ; \dagger P=.62 ; \ddagger P=.48$.

carcinoembryonic antigen values, preoperative tumor size, and $\mathrm{SUV}_{\max }$ values. Regarding pathologic findings, LI status had no association with the LC ratio, blood vessel invasion, and pleural invasion. Additionally, LI status had no correlation with lymph node metastasis status, both single or multiple station metastases (Table 4).

\section{DISCUSSION}

In this study, $\mathrm{pN}(+) / \mathrm{LI}(-)$ patients had a better prognosis than $\mathrm{pN}(+) / \mathrm{LI}(+)$ patients, whereas there were no significant differences in the RFS between $\mathrm{pN}(+) / \mathrm{LI}(-)$ and $\mathrm{pN}(-) / \mathrm{LI}(+)$ clinical stage IA lung adenocarcinoma patients at the participating institutions. LI status, which is 
TABLE 2. Univariate log-rank analysis of recurrence-free survival (RFS) and overall survival (OS) according to various factors in patients with lung adenocarcinoma

\begin{tabular}{|c|c|c|c|c|c|c|}
\hline \multirow[b]{2}{*}{ Pathologic variable } & \multicolumn{2}{|c|}{ All } & \multicolumn{2}{|c|}{ Node negative } & \multicolumn{2}{|c|}{ Node positive } \\
\hline & 3-y RFS rate (\%) & $P$ value & 3-y RFS rate (\%) & $P$ value & 3-y RFS rate $(\%)$ & $P$ value \\
\hline \multicolumn{7}{|l|}{$\mathrm{LC}$ ratio } \\
\hline$\geq 30$ & 95.2 & $<.0001$ & 95.9 & $<.0001$ & 57.1 & .93 \\
\hline$<30$ & 78.2 & & 81.4 & & 60.5 & \\
\hline \multicolumn{7}{|l|}{ Lymphatic invasion } \\
\hline Negative & 93.1 & $<.0001$ & 93.4 & $<.0001$ & 84.6 & .059 \\
\hline Positive & 63.7 & & 70.8 & & 47.9 & \\
\hline \multicolumn{7}{|l|}{ Blood vessel invasion } \\
\hline Negative & 93.1 & $<.0001$ & 94.3 & $<.0001$ & 58.8 & .93 \\
\hline Positive & 63.7 & & 71.0 & & 60.6 & \\
\hline \multicolumn{7}{|l|}{ Pleural invasion } \\
\hline Negative & 93.1 & $<.0001$ & 92.6 & $<.0001$ & 57.1 & .42 \\
\hline Positive & 68.6 & & 74.6 & & 65.6 & \\
\hline \multicolumn{7}{|l|}{ Lymph node metastasis } \\
\hline Negative & 90.9 & $<.0001$ & 90.9 & - & - & - \\
\hline \multirow[t]{3}{*}{ Positive } & 59.9 & & - & & 59.9 & \\
\hline & \multicolumn{2}{|c|}{ All } & \multicolumn{2}{|c|}{ Node negative } & \multicolumn{2}{|c|}{ Node positive } \\
\hline & 3-y OS rate $(\%)$ & $P$ value & 3-y OS rate (\%) & $P$ value & 3-y OS rate (\%) & $P$ value \\
\hline \multicolumn{7}{|l|}{$\mathrm{LC}$ ratio } \\
\hline$\geq 30$ & 97.0 & $<.0001$ & 97.3 & $<.0001$ & 75.0 & .76 \\
\hline$<30$ & 90.9 & & 92.0 & & 84.5 & \\
\hline \multicolumn{7}{|l|}{ Lymphatic invasion } \\
\hline Negative & 96.6 & $<.0001$ & 96.7 & $<.0001$ & 92.3 & .490 \\
\hline Positive & 83.5 & & 85.1 & & 75.0 & \\
\hline \multicolumn{7}{|l|}{ Blood vessel invasion } \\
\hline Negative & 96.4 & $<.0001$ & 96.7 & $<.0001$ & 88.2 & .55 \\
\hline Positive & 86.5 & & 88.1 & & 81.0 & \\
\hline \multicolumn{7}{|l|}{ Pleural invasion } \\
\hline Negative & 94.9 & .0042 & 95.9 & $<.0001$ & 100.0 & .29 \\
\hline Positive & 92.7 & & 91.2 & & 77.3 & \\
\hline \multicolumn{7}{|l|}{ Lymph node metastasis } \\
\hline Negative & 95.5 & $<.0001$ & 95.5 & - & - & - \\
\hline Positive & 83.6 & & - & & 83.6 & \\
\hline
\end{tabular}

$L C$, Lepidic component; $R F S$, recurrence-free survival; $O S$, overall survival.

not always positive in $\mathrm{N}+$ patients, is a significant predictive factor in patients with pathologic lymph node metastasis, whereas the lymph node metastasis status is a strong prognostic factor in patients with clinical T1 N0 M0 lung adenocarcinoma.

It is reasonable that lymph node metastasis occurs after cancer cells invade the lymphatic vessels around the tumors; however, 13 of $41(31.7 \%)$ patients with lung adenocarcinoma, whose LI status was negative, exhibited metastasis to regional lymph nodes. One possible explanation is the difficulty in examining all slices of a specimen; some of the slices, including the tumor, could be pathologically assessed. This could be missed if tumors had only slight LI, and the LI status would be determined as negative. Therefore, "no pathologic LI" could either mean no massive LI, just a slight invasion, or it could mean that there was indeed no LI. This is especially the case in $\mathrm{pN}+$ patients, where "no pathologic LI" indicates a slight LI. Slight invasion means the initial period of lymphatic vessel invasion and lymph node metastasis; therefore, patients with slight invasion had a better prognosis than those with massive invasion after complete surgical resection. In $\mathrm{pN}+$ patients the $\mathrm{N} 1$ rate was higher in $\mathrm{pN}(+) / \mathrm{LI}(-)$ patients compared with $\mathrm{pN}(+) / \mathrm{LI}(+)$ patients, albeit nonsignificantly so. This suggests that $\mathrm{pN}(+) / \mathrm{LI}(-)$ is indicative of initial lymph node metastasis, as described above.

In $\mathrm{pN}+$ patients, the $\mathrm{N} 2: \mathrm{N} 1$ ratio was higher in $\mathrm{pN}(+)$ $\mathrm{LI}(+)$ than $\mathrm{pN}(+) \mathrm{LI}(-)$ patients, although the difference was not statistically significant. The number of $\mathrm{pN}+$ patients was too small to draw any conclusion; however, the tumors that showed massive LI had a higher tendency to progress to $\mathrm{N} 2$ disease than $\mathrm{LI}(-)$ tumors. Patients with 
TABLE 3. Multivariate Cox regression analysis of recurrence-free survival according to various factors

\begin{tabular}{|c|c|c|c|c|c|c|}
\hline \multirow[b]{2}{*}{ Pathologic variables } & \multicolumn{2}{|c|}{ All } & \multicolumn{2}{|c|}{ Node negative } & \multicolumn{2}{|c|}{ Node positive } \\
\hline & HR & $P$ value & HR & $P$ value & HR & $P$ value \\
\hline $\mathrm{LC}$ ratio & 0.44 & .010 & 0.39 & .008 & 1.7 & .62 \\
\hline$>30$ vs $<30$ & $0.23-0.82$ & & $0.20-0.78$ & & $0.44-6.3$ & \\
\hline Lymphatic invasion & 2.5 & .001 & 1.9 & .045 & 6.1 & .037 \\
\hline Positive vs negative & $1.4-4.3$ & & $1.0-3.5$ & & $1.3-28.7$ & \\
\hline Blood vessel invasion & 1.8 & .037 & 2.0 & .031 & 0.87 & .61 \\
\hline Positive vs negative & $1.0-3.1$ & & $1.1-3.8$ & & $0.31-2.4$ & \\
\hline Pleural invasion & 1.6 & .11 & 2.1 & .024 & 0.47 & .19 \\
\hline Positive vs negative & $0.91-2.7$ & & $1.1-3.9$ & & $0.14-1.5$ & \\
\hline Lymph node metastasis & 1.9 & .032 & —* & 一* & —* & —* \\
\hline Positive vs negative & $1.1-3.4$ & & & & & \\
\hline
\end{tabular}

$L C$, Lepidic component; $H R$, hazard ratio. *Not calculated.

micrometastatic disease to the lymph nodes have been demonstrated to have a worse prognosis than patients with lymph nodes completely replaced by tumors. ${ }^{15}$ This suggests that the continuum from LI to lymph node micrometastasis to lymph node replacement might be more complex than previously believed.

As in previous reports, in all patients, multivariate analysis of RFS revealed a lower LC ratio, positive status of lymph nodes, LI, blood vessel invasion, pleural invasion and were poor prognostic factors as well as $\mathrm{N}+$ status in this study. ${ }^{16,17}$ In contrast, all evaluated pathologic variables, except for LI status, did not show potential as predictive factors for patients with lymph node involvement. Although lymphatic metastasis status was a strong prognostic factor, LI status was also a significant predictive factor of prognosis in patients with clinical stage IA lung adenocarcinoma. In $\mathrm{pN}+$ patients, LI status had no association with either the clinical or pathologic findings. Thus, the above findings strongly support the significance of LI status as a predictive factor, particularly in patients whose lymph node status is clinically negative and pathologically positive. That is, poor prognosis should be defined according to not only lymph node status but also LI status. Other unknown factors may more precisely determine the true patient population with a poor prognosis. Although $\mathrm{pN}+$ patients typically receive adjuvant chemotherapy, such patients may be classified into no-adjuvant, mild-adjuvant, and severeadjuvant groups using several predictive factors, including LI status.

Two previous reports have demonstrated that LI status is a poor prognostic factor in surgically resected non-small cell lung cancer ${ }^{18,19}$ and a similar result was shown in pathologic stage I or adenocarcinoma patients. Additionally, LI status has been demonstrated to be a prognostic factor regardless of lymph node status. ${ }^{18,19}$ However, these previous studies had some limitations; 1 was the quality of LI status evaluation. LI status was evaluated using D2-40 immunostaining in this study, whereas only some tumors were assessed for LI status using D2-40 in the report ${ }^{19}$ and the other did not distinguish LI from blood vessel invasion. ${ }^{18}$ Thus, the quality of LI evaluation was higher in our study. Another limitation is heterogeneity of the cohort. The analysis was performed only in pathologic stage I patients in the previous studies to minimize heterogeneity. ${ }^{18,19}$ However, that analysis of pathologic stage I patients could not assess LI status in $\mathrm{pN}+$ patients. In our study, we evaluated LI status with little heterogeneity in $\mathrm{pN}+$ patients because we included only clinical stage IA adenocarcinoma patients having little heterogeneity.

The rate of lymph node involvement was $6.7 \%$ of clinical stage IA lung adenocarcinoma patients in our study (41 out of 609 cases). PET/CT examination has been shown to provide the most accurate preoperative diagnosis ${ }^{1,4}$ and results in appropriate treatment. However, a new diagnostic method is necessary to evaluate more accurately the preoperative status of patients with clinical stage IA adenocarcinoma and pathologic lymph node involvement whose preoperative diagnostic modality included a PET scan.

Few patients had lymph node metastasis in clinical stage IA lung adenocarcinoma, which represents one of the main limitations of this study; only a very small number of patients with lymph node involvement had a negative LI status. This makes it difficult to conclude that the prognosis of $\mathrm{pN}(+) \mathrm{LI}(-)$ patients is equivalent to that of $\mathrm{pN}(-)$ $\mathrm{LI}(+)$ patients; however, it cannot be denied that LI status plays an important role in assessing patients with lymph node metastasis. The lack of data about pathologic tumor size or morbidity are also limitations of our study. Another is that detailed numbers on patients who received postoperative chemotherapy were not available. Postoperative chemotherapy was performed when pathologic upstaging or recurrence was detected. Additionally, although the follow-up time was too short to assess OS in this study, the OS curves showed similar tendencies to RFS. Because a previous study reported that RFS could be a surrogate 
TABLE 4. Clinicopathologic findings in patients with clinical stage IA but pathologic lymph node positive lung adenocarcinoma, according to lymphatic invasion status

\begin{tabular}{|c|c|c|c|}
\hline \multirow[b]{2}{*}{ Finding } & \multicolumn{2}{|c|}{ Lymph node metastasis positive } & \multirow[b]{2}{*}{$\begin{array}{c}P \\
\text { value } \\
\end{array}$} \\
\hline & $\begin{array}{c}\text { Lymphatic } \\
\text { invasion } \\
\text { negative } \\
(\mathbf{n}=\mathbf{1 3}) \\
\end{array}$ & $\begin{array}{c}\text { Lymphatic } \\
\text { invasion } \\
\text { positive } \\
(\mathbf{n}=\mathbf{2 8}) \\
\end{array}$ & \\
\hline \multicolumn{4}{|l|}{ Age } \\
\hline Median & 64 & 66 & .96 \\
\hline Interquartile range & $56-72$ & $55.25-73.25$ & \\
\hline \multicolumn{4}{|l|}{ Sex } \\
\hline Female & 4 & 15 & .20 \\
\hline Male & 9 & 13 & \\
\hline \multicolumn{4}{|l|}{ CEA } \\
\hline Median & 3.7 & 3.4 & .81 \\
\hline Interquartile range & $2.5-4.075$ & $2.65-4.25$ & \\
\hline \multicolumn{4}{|l|}{ Size* } \\
\hline Median & 2 & 2.2 & .62 \\
\hline Interquartile range & $1.6-2.6$ & $1.775-2.5$ & \\
\hline \multicolumn{4}{|l|}{$\mathrm{GGO} \dagger$ ratio } \\
\hline Median & 0 & 0 & .75 \\
\hline Interquartile range & $0-10$ & $0-2.5$ & \\
\hline \multicolumn{4}{|l|}{ SUV max } \\
\hline Median & 3.4 & 3.7 & .87 \\
\hline Interquartile range & $2.7-4.0$ & $2.175-4.925$ & \\
\hline \multicolumn{4}{|l|}{$\mathrm{LC}$ ratio } \\
\hline Median & 10 & 10 & .16 \\
\hline Interquartile range & $10-20$ & $0-12.5$ & \\
\hline \multicolumn{4}{|l|}{ Blood vessel invasion } \\
\hline Negative & 7 & 10 & .32 \\
\hline Positive & 6 & 18 & \\
\hline \multicolumn{4}{|l|}{ Pleural invasion } \\
\hline Negative & 11 & 18 & .28 \\
\hline Positive & 2 & 10 & \\
\hline \multicolumn{4}{|l|}{ Lymph node metastasis } \\
\hline N1 & 9 & 11 & .18 \\
\hline $\begin{array}{l}\text { Single station } \mathrm{N} 2 \text { or single } \\
\text { station } \mathrm{N} 2+\mathrm{N} 1\end{array}$ & 2 & 11 & \\
\hline Multistation N2 & 2 & 6 & \\
\hline
\end{tabular}

$C E A$, Carcinoembryonic antigen; $G G O$, ground-glass opacity; $S U V$, standardized uptake value; $L C$, lepidic component. *Tumor size on the high-resolution computed tomography scan. $\nmid G G O$ ratio on the high-resolution computed tomography scan.

for $\mathrm{OS},{ }^{20}$ to evaluate RFS may effectively be equivalent to assessing OS in identifying prognostic factors.

\section{CONCLUSIONS}

LI was not always present in $\mathrm{pN}+$ adenocarcinoma patients. In addition, $\mathrm{pN}(+) \mathrm{LI}(-)$ patients had a better prognosis than $\mathrm{pN}(+) \mathrm{LI}(+)$ patients, whereas there was no significant difference in $\mathrm{RFS}$ between $\mathrm{pN}(+) \mathrm{LI}(-)$ and $\mathrm{pN}(-) \mathrm{LI}(+)$ patients with clinical stage IA lung adenocarcinoma. LI status was indicated to classify clinical T1 N0 M0 lung adenocarcinoma patients with and without lymph node involvement into good and poor prognosis groups, the preoperative staging of which conducted using high-resolution
CT and FDG-PET/CT. LI status may affect the selection of patients who have to receive adjuvant therapy.

\section{References}

1. Lardinois D, Weder W, Hany TF, Kamel EM, Korom S, Seifert B, et al. Staging of non-small-cell lung cancer with integrated positron-emission tomography and computed tomography. N Engl J Med. 2003;348:2500-7.

2. Okada M, Nakayama H, Okumura S, Daisaki H, Adachi S, Yoshimura M, et al. Multicenter analysis of high-resolution computed tomography and positron emission tomography/computed tomography findings to choose therapeutic strategies for clinical stage IA lung adenocarcinoma. J Thorac Cardiovasc Surg. 2011;141:1384-91.

3. Tsutani Y, Miyata Y, Nakayama H, Okumura S, Adachi S, Yoshimura M, et al. Prediction of pathologic node-negative clinical stage IA lung adenocarcinoma for optimal candidates undergoing sublobar resection. J Thorac Cardiovasc Surg. 2012;144:1365-71.

4. Shim SS, Lee KS, Kim BT, Chung MJ, Lee EJ, Han J, et al. Non-small cell lung cancer: prospective comparison of integrated FDG PET/CT and CT alone for preoperative staging. Radiology. 2005;236:1011-9.

5. Kim BT, Lee KS, Shim SS, Choi JY, Kwon OJ, Kim H, et al. Stage T1 non-small cell lung cancer: preoperative mediastinal nodal staging with integrated FDG PET/CT - a prospective study. Radiology. 2006;241:501-9.

6. Yi CA, Lee KS, Kim BT, Shim SS, Chung MJ, Sung YM, et al. Efficacy of helical dynamic CT versus integrated PET/CT for detection of mediastinal nodal metastasis in non-small cell lung cancer. AJR Am J Roentgenol. 2007;188:318-25.

7. Lee SM, Park CM, Paeng JC, Im HJ, Goo JM, Lee HJ, et al. Accuracy and predictive features of FDG-PET/CT and CT for diagnosis of lymph node metastasis of T1 non-small-cell lung cancer manifesting as a subsolid nodule. Eur Radiol. 2012;22:1556-63.

8. Goldstraw P, Crowley J, Chansky K, Giroux DJ, Groome PA, Rami-Porta R, et al. The IASLC Lung Cancer Staging Project: proposals for the revision of the TNM stage groupings in the forthcoming (seventh) edition of the TNM Classification of malignant tumours. J Thorac Oncol. 2007;2:706-14.

9. Suzuki K, Koike T, Asakawa T, Kusumoto M, Asamura H, Nagai K, et al. A prospective radiological study of thin-section computed tomography to predict pathological noninvasiveness in peripheral clinical IA lung cancer (Japan Clinical Oncology Group 0201). J Thorac Oncol. 2011;6:751-6.

10. Travis WD, Brambilla E, Muller-Hermelink HK, Harris CC. Pathology and genetics tumors of the lung, pleura, thymus and heart. In: World Health Organization classification of tumours. Lyon, France: IARC Press; 2004.

11. Nakayama H, Okumura S, Daisaki H, Kato Y, Uehara H, Adachi S, et al. Value of integrated positron emission tomography revised using a phantom study to evaluate malignancy grade of lung adenocarcinoma: a multicenter study. Cancer. 2010;116:3170-7.

12. Delbeke D, Coleman RE, Guiberteau MJ, Brown ML, Royal HD, Siegel BA, et al. Procedure guideline for tumor imaging with 18F-FDG PET/CT 1.0. J Nucl Med. 2006;47:885-95.

13. Li L, Ren S, Zhang Y, Guan Y, Zhao J, Liu J, et al. Risk factors for predicting the occult nodal metastasis in T1-2N0M0 NSCLC patients staged by PET/CT: potential value in the clinic. Lung Cancer. 2013;81:213-7.

14. Kanda Y. Investigation of the freely available easy-to-use software 'EZR' for medical statistics. Bone Marrow Transplant. 2013;48:452-8.

15. Riquet M, Bagan P, Le Pimpec Barthes F, Banu E, Scotte F, Foucault C, et al. Completely resected non-small cell lung cancer: reconsidering prognostic value and significance of N2 metastases. Ann Thorac Surg. 2007;84:1818-24.

16. Funai K, Sugimura H, Morita T, Shundo Y, Shimizu K, Shiiya N. Lymphatic vessel invasion is a significant prognostic indicator in stage IA lung adenocarcinoma. Ann Surg Oncol. 2011;18:2968-72.

17. Kudo Y, Saji H, Shimada Y, Nomura M, Matsubayashi J, Nagao T, et al. Impact of visceral pleural invasion on the survival of patients with non-small cell lung cancer. Lung Cancer. 2012;78:153-60.

18. Higgins KA, Chino JP, Ready N, D'Amico TA, Berry MF, Sporn T, et al. Lymphovascular invasion in non-small-cell lung cancer: implications for staging and adjuvant therapy. J Thorac Oncol. 2012;7:1141-7.

19. Wang J, Wang B, Zhao W, Guo Y, Chen H, Chu H, et al. Clinical significance and role of lymphatic vessel invasion as a major prognostic implication in non-small cell lung cancer: a meta-analysis. PloS One. 2012;7:e52704.

20. Gill S, Sargent D. End points for adjuvant therapy trials: has the time come to accept disease-free survival as a surrogate end point for overall survival? Oncologist. 2006;11:624-9. 